\title{
Enhancement of Recovery with Physical Therapy Management in Patient of Rare Variety of Gullain Barre Syndrome: A Case Report
}

\author{
Snehal Waghavkar ${ }^{1 *}$ and Suvarna Ganvir ${ }^{2}$
}

${ }^{1}$ Physiotherapy (Neurosciences), PDVVPF's COPT, Ahmednagar, India

${ }^{2}$ Department of Neuroscieces, Physiotherapy, PDVVPF's COPT, Ahmednagar, India

\begin{abstract}
Guillain-Barre Syndrome (GBS) is an immune mediated peripheral neuropathy as it is caused by the body's immune system mistakenly attacking the peripheral nerves and damaging their myelin insulation. Sometimes this immune dysfunction is triggered by an infection primarily characterized by rapidly evolving symmetrical limb weakness. The weakness can be variable, from minimal lower extremity weakness to total paralysis of all extremities and trunk. Symptoms become more severe until they reach maximum expression, called the nadir; a plateau phase of 2-4 weeks follows, and recovers completely within 1 month after the onset. But in rare cases there is a gradual resolution of the paralysis that can last 1-2 years and the patient recovers within a period of 6 months to 2 years. The patient being reported in this case study is a 40 year old male diagnosed with GBS and reached a plateau phase within a month and recovery is not complete even after 6 months (till today). The aim of this study was to report the effect of Physical therapy management for enhancement of recovery in patient with rare variety of Gullain Barre Syndrome. 40 year old patient diagnosed as a case of GBS was referred to Physiotherapy, Vikhe Patil Memorial Hospital, Ahmednagar 6 months back. It was expected that recovery would occur within a period of maximum 12 weeks. The patient was received Proprioceptive Neuromuscular Reeducation, Therapeutic Exercises in supine and Sitting, Electrical Muscle stimulation (Faradic stimulation to Quads and IG to intrinsic muscles of hand and foot) and bed mobility training. Outcome measures were MMT, Barthel Index, and Functional Indepedence Measure and DeMorton Mobility Index. The result of case report showed that there was statistically significant improvement in all outcome measures which includes MMT, Barthel Index, and Functional Indepedence Measure and DeMorton Mobility Index. Hence, the study concluded that the recovery in patients with GBS may be delayed in contrast to the reported literature and may take more than 6 months as in the present case.
\end{abstract}

Keywords: Gullain barre syndrome; Proprioceptive neuromuscular re-education; Manual muscle testing; Functional independence measure; DeMorton mobility index

\section{Introduction}

Guillain-Barré Syndrome (GBS) is an immune mediated peripheral neuropathy primarily characterized by rapidly evolving symmetrical limb weakness [1]. The weakness can be variable, from minimal lower extremity weakness to total paralysis of all extremities and trunk. Symptoms become more severe until they reach maximum expression, called the nadir; a plateau phase of 2-4 weeks follows, and recovers completely within 1 month after the onset. But in rare cases there is a gradual resolution of the paralysis that can last 1-2 years and the patient recovers within a period of 6 months to 2 years [2]. The patient being reported in this case study is a 40 year old male diagnosed with GBS and reached a plateau phase within a month and recovery is not complete even after 5 months (till today).

\section{Purpose}

The purpose of this report is to find out enhancement of recovery with Physical therapy Management in patient of rare variety of Gullain Barre Syndrome. Patient was admitted to Vikhe Patil Memorial Hospital on June $30^{\text {th }}, 2015$ and was seen for physical therapy evaluation the following day, $1^{\text {st }}$ July, 2015 . He is a 40 year old Labourer male standing 5'8" tall and weighing $64 \mathrm{~kg}$ on admission. His past history had not been significant for hypertension, asthama, and diabetes mellitus. But, History of viral fever with cough and cold in the month of March before onset of present condition. The patient does have a history of tobacco chewing 1 packet/day since 20 years but denies any current smoking or illicit drugs and admits to occasional alcohol of approximately 1-2 drinks per week. Family history was not significant. Patient is married and reports living with his wife and two children. Systems review upon admission indicated the patient denied any headache, vision or hearing changes, dysphagia, nasal discharge, chest pain, shortness of breath, productive cough, palpitations, abdominal pain, nausea, vomiting, diarrhea, melena, urinary changes of any sort, unintentional weight gain or loss, subjective fevers or chills or hot or cold intolerances. At admission, patient alert and oriented $\times 3[3,4]$, pleasant, with no limitations to communication ability. Current medications included Neurobion Forte, Pantosec. The preceding information was provided through chart review and patient interview. History of current condition was obtained directly from patient interview and is as follows: On April 29, 2015 patient indicates had slight increase in temperature. On next day morning the patient experienced left upper extremity weakness while having his food and dropped food items due to weakness. The following day he noted difficulty walking including weakness, shuffling and a general unsteadiness. So, his relatives took him to a hospital in Nashik. On next day morning there was no movements in bilateral upper and lower extremities and lost his ability

*Corresponding author: Snehal Waghavkar, PG Student, Physiotherapy (Neurosciences), PDVVPF's COPT, Ahmednagar, India, Tel: 7276520468; E-mail: snehalnw22@gmail.com.

Received: March 07, 2016; Accepted: April 18, 2016; Published: April 25, 2016

Citation: Waghavkar S, Ganvir S (2016) Enhancement of Recovery with Physical Therapy Management in Patient of Rare Variety of Gullain Barre Syndrome: A Case Report. Physiother Rehabil 1: 107. doi:10.4172/2573-0312.1000107

Copyright: () 2016 Waghavkar S, et al. This is an open-access article distributed under the terms of the Creative Commons Attribution License, which permits unrestricted use, distribution, and reproduction in any medium, provided the original author and source are credited. 
Citation: Waghavkar S, Ganvir S (2016) Enhancement of Recovery with Physical Therapy Management in Patient of Rare Variety of Gullain Barre Syndrome: A Case Report. Physiother Rehabil 1: 107. doi: 10.4172/2573-0312.1000107

Page 2 of 4

to sit upright by his own. CSF Examination was done which shows increased CPK level indicates GBS. GBS have an elevated cerebrospinal fluid (CSF) protein level (>400 mg/L), with normal CSF cell counts. As over there he received 8 settings of plasmapheresis and physical therapy management comprised of passive movements. He was subsequently transferred to Vikhe patil Memorial Hospital for a higher level of care and physiotherapy management.

Patient stated that his goal for therapy was to walk without the use of an assistive device and be able to carry basic activities of daily living s/a independent with showering and toileting.

\section{Intervention}

The plan of care for patient's included PT 6 days per week with 1 hours of therapy twice a day which include: Individual Joint compression to finger and wrist to UE and fingers and ankle to LE., standing on a tilt table with support $\times 15$ mins, Faradic re-education to Bilateral quadriceps $\times 5$ mins, EMS on IG to bilateral adductor pollicis, $1^{\text {st }}$ dorsal interossei, tibialis anterior and extensor hallucis muscles $\times$ 45 contractions to each, Proprioceptive Neuromuscular Re eduaction includes: D1 and D2 flexion and extension pattern for UE (Timing for Emphasis), Rhythmic stabilization for pelvis and scapula, D2 Extension pattern for LE (Timing for Emphasis), Bed mobility training, safety education, Therapeutic interventions included exercises in supine: bridging (with and without a ball between knees for adduction, and with and without DF upon elevation); quad sets initially with advancement to short arc quads; heel slides; practice supine $\leftrightarrow$ sit and rolling activities with verbal cues for technique and safety to increase functional mobility. Seated therapeutic activities including marching in place (hip flexion); knee flexion; heel/toe raises; hip ab/adduction; sit to stands and glut sets. Pain relief modalities (MHT) to bilateral shoulders (Figures 1-6).

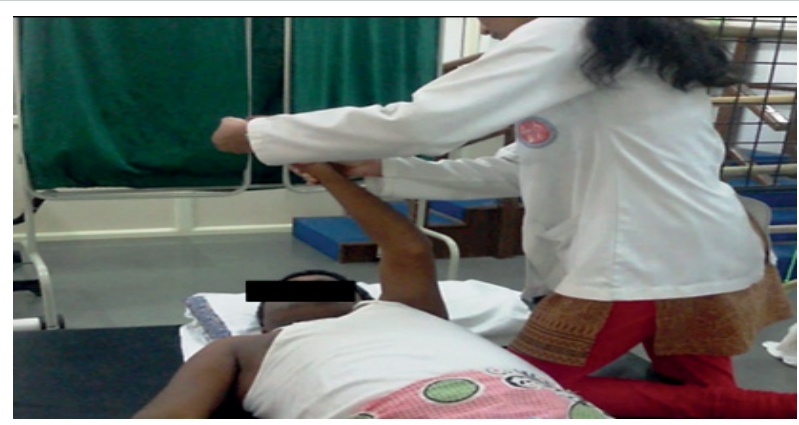

Figure 1: UE D1 flexion.

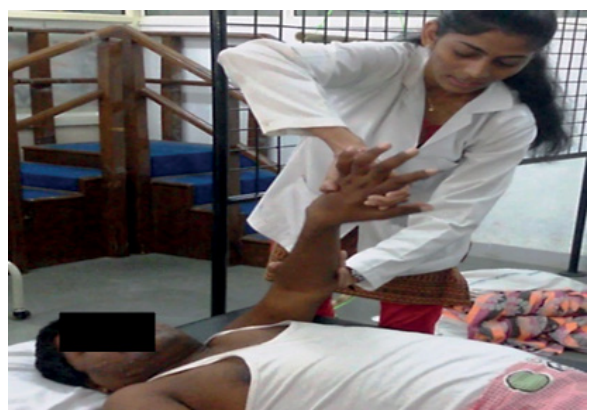

Figure 2: UE D2 extension.

\section{Evaluation}

Evaluation of results can be seen in Tables 1 and 2.

\section{Results}

The result of case report showed that there was statistically significant improvement in all outcome measures which includes MMT, Barthel Index, Functional Indepedence Measure and DeMorton Mobility Index. Pre MMT mean score $(0.43+1.134)$ and Post MMT mean score $(3.149+1.58)(\mathrm{p}<0.0020)$. Initially the Barthel Index score was $4 / 20$ which was improved to $10 / 20$. The initial FIM score was 41 out of 126 which was improved to 69 (there was more improvement in mobility component of FIM). The DeMorton Mobility Index score showed significant improvment as initially it was $0 / 100$, which was improved to $39 / 100$ (Figures 7-9).

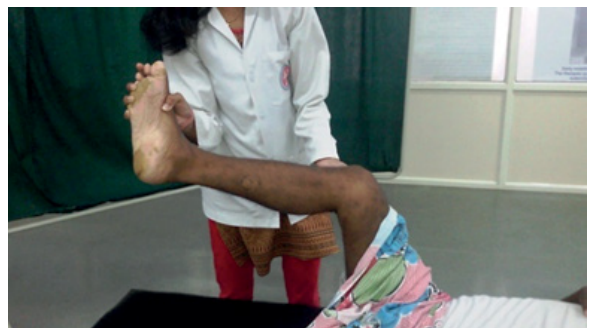

Figure 3: LE D1 flexion.

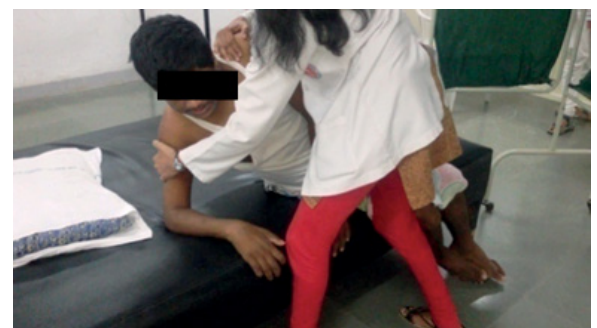

Figure 4: Functional reeducation from side lying to sitting

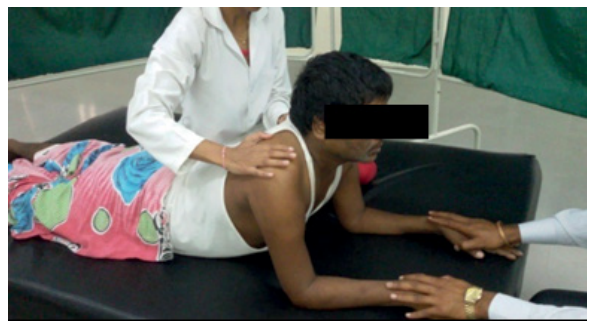

Figure 5: Rhythmic stabilization to scapula

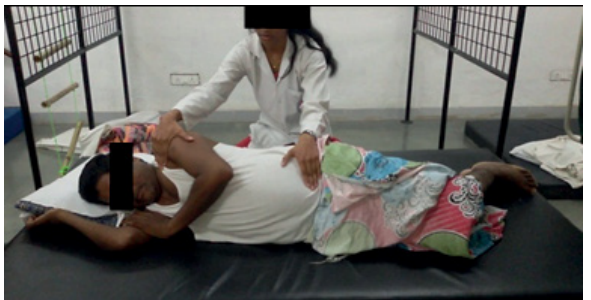

Figure 6: Rhythmic stabilization to improve rolling 
Citation: Waghavkar S, Ganvir S (2016) Enhancement of Recovery with Physical Therapy Management in Patient of Rare Variety of Gullain Barre Syndrome: A Case Report. Physiother Rehabil 1: 107. doi: 10.4172/2573-0312.1000107

Page 3 of 4

\begin{tabular}{|c|c|c|c|c|c|c|}
\hline Test and Measures & Tone & DTR & MMT & Bartel Index & FIM \\
\hline At initial examination & Flaccidity (Grade 0) & 0 X 4 Extremities & $\begin{array}{c}\text { Weakness distal } \geq \\
\text { proximal }\end{array}$ & $\begin{array}{c}4 / 20 \text { (Complete } \\
\text { Dependent) }\end{array}$ & $\begin{array}{c}41 / 126(\text { Complete } \\
\text { Dependence) }\end{array}$ & $\begin{array}{c}0 / 100 \text { (Complete } \\
\text { Dependent Mobility) }\end{array}$ \\
\hline At Present & Hypotonia (Grade 1+) & $1^{+}$X 4 Extremities & $\begin{array}{c}\text { Predominately distal } \\
\text { weakness only }\end{array}$ & $\begin{array}{c}10 / 20 \text { (Moderately } \\
\text { Dependent) }\end{array}$ & $\begin{array}{c}69 / 126(\text { Moderate } \\
\text { Dependence) }\end{array}$ & $\begin{array}{c}39 / 100 \text { (Moderate } \\
\text { Dependent Mobility) }\end{array}$ \\
\hline
\end{tabular}

Table 1: Test and measurement of DTR, MMT, Bartel index, FIM, DeMorton mobility index.

\begin{tabular}{|c|c|c|c|c|}
\hline \multirow{2}{*}{ Manual Muscle Test } & \multicolumn{2}{|c|}{ LEFT } & \multicolumn{2}{|c|}{ RIGHT } \\
\hline & Initial Examination & At Present & Initial Examination & At Present \\
\hline Scapular Protractors & Poor & Good & Poor & Good \\
\hline Scapular Retractors & Poor & Good & Poor & Good \\
\hline Scapular Elevators & Poor & Good & Poor & Good \\
\hline Scapular Depressors & Poor & Good & Poor & Good \\
\hline Neck Flexors & \multicolumn{2}{|c|}{3} & \multicolumn{2}{|c|}{5} \\
\hline Neck Extensors & \multicolumn{2}{|c|}{3} & \multicolumn{2}{|c|}{5} \\
\hline Neck Lateral Flexors & 3 & 5 & 3 & 5 \\
\hline Neck Rotators & 3 & 5 & 3 & 5 \\
\hline Shoulder Flexors & 0 & 5 & 0 & 5 \\
\hline Shoulder Extensors & 0 & 5 & 0 & 3 \\
\hline Shoulder Abductors & 0 & 5 & 0 & 5 \\
\hline Shoulder Internal Rotators & 0 & 5 & 0 & 5 \\
\hline Shoulder External Rotators & 0 & 5 & 0 & 5 \\
\hline Elbow Flexors & 0 & 4 & 0 & 4 \\
\hline Elbow Extensors & 0 & 4 & 0 & 4 \\
\hline Forearm Supinators & 0 & 4 & 0 & 4 \\
\hline Forearm Pronators & 0 & 4 & 0 & 4 \\
\hline Wrist Flexors & 0 & 2 & 0 & 2 \\
\hline Wrist Extensors & 0 & 1 & 0 & 1 \\
\hline Wrist UInar Deviators & 0 & 2 & 0 & 2 \\
\hline Wrist Radial Deviators & 0 & 1 & 0 & 1 \\
\hline Finger Flexors & 0 & 2 & 0 & 2 \\
\hline Finger Extensors & 0 & 1 & 0 & 1 \\
\hline Hip Flexors & 0 & 3 & 0 & 3 \\
\hline Hip Extensors & 0 & 3 & 0 & 3 \\
\hline Hip Abductors & 0 & 3 & 0 & 3 \\
\hline Hip Internal Rotators & 0 & 3 & 0 & 3 \\
\hline Hip External Rotators & 0 & 3 & 0 & 3 \\
\hline Knee Flexors & 0 & 3 & 0 & 3 \\
\hline Knee Extensors & 0 & 3 & 0 & 3 \\
\hline Ankle Dorsiflexors & 0 & 1 & 0 & 1 \\
\hline Ankle Plantarflexors & 0 & 3 & 0 & 3 \\
\hline
\end{tabular}

Table 2: Manual measuring test.

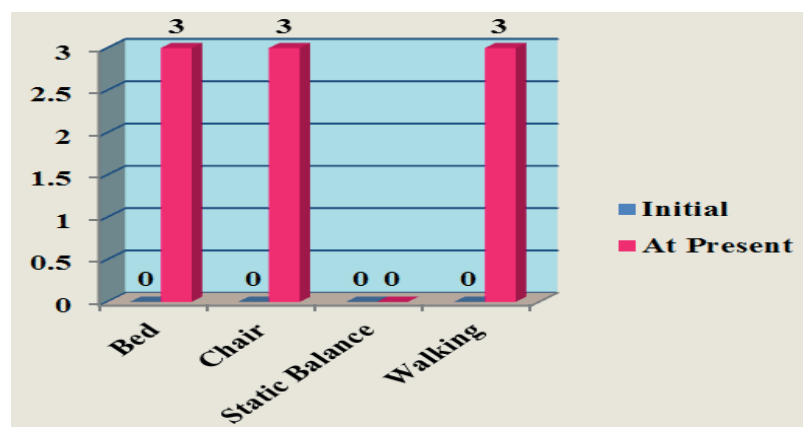

Figure 7: DeMorton mobility index score.

\section{Discussion}

The significance of this case report was the rare opportunity to document the outcome of a PT intervention for rare condition of GBS.

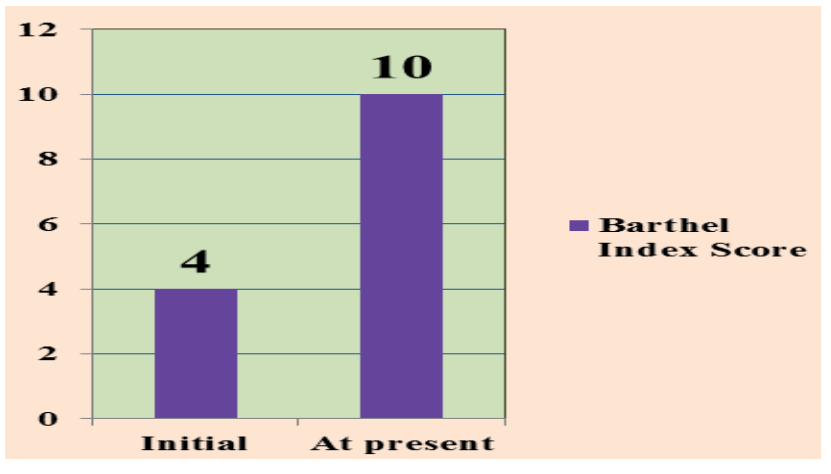

Figure 8: Barthel index score.

At the present the patient achieved good bed mobility and transfer and will able to return to his prior functional status within few weeks. Therefore, the use of PT intervention is beneficial for enhancement of 


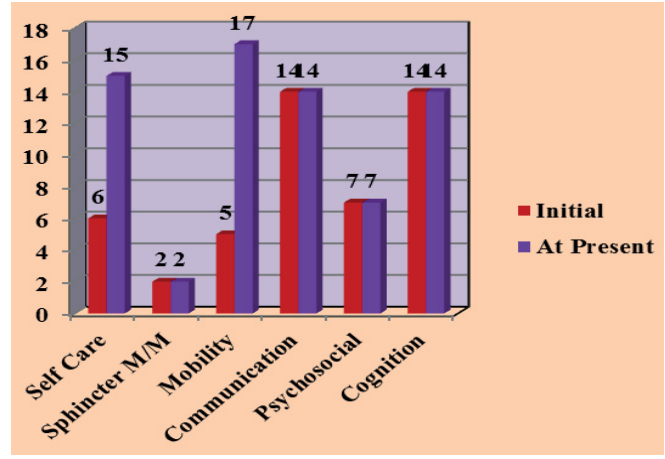

Figure 9: FIM score. recovery in rare variety of GBS. Future work in this area could compare and contrast the outcomes of other PT intervention for enhancement of recovery in rare variety of GBS.

\section{Conclusion}

Recovery in patients with GBS may be delayed in contrast to the reported literature and may take more than 6 months as in the present case.

\section{References}

1. (2014) National Institute of Neurological Disorders and Stroke. Guillain-Barre Syndrome fact sheet.

2. (2014) World Health Organization. The ICF: An overview.

3. O'Sullivan S (2013) Text book of Physical Rehabilitation (6 $6^{\text {th }}$ edn.).

4. Umphred DA (2012) Text book of Neurological Rehabilitation (6 $6^{\text {th }}$ edn.). 